\title{
Genetics of Parkinson's disease in the Polish population
}

\author{
Łukasz M. Milanowski ${ }^{1,2,3}$, Owen A. Ross ${ }^{2}$, Andrzej Friedman ${ }^{3}$, Dorota Hoffman-Zacharska ${ }^{4}$, \\ Paulina Gorka-Skoczylas ${ }^{4}$, Marta Jurek ${ }^{4}$, Dariusz Koziorowski ${ }^{3}$, Zbigniew K. Wszolek ${ }^{1}$ \\ ${ }^{1}$ Department of Neurology, Mayo Clinic, Jacksonville, Florida, United States \\ ${ }^{2}$ Department of Neuroscience, Mayo Clinic, Jacksonville, Florida, United States \\ ${ }^{3}$ Department of Neurology, Faculty of Health Science, Medical University of Warsaw, Warsaw, Poland \\ ${ }^{4}$ Department of Medical Genetics, Institute of Mother and Child, Warsaw, Poland
}

\begin{abstract}
Introduction. Genetic forms of Parkinson's disease (PD) often cluster in different ethnic groups and may present with recognisable unique clinical manifestations. Our aim was to summarise the current state of knowledge regarding the genetic causes of PD and describe the first Polish patient with SNCA duplication.

Methodology. We searched the electronic database, PubMed, for studies between January 1995 and June 2020 that evaluated genetics in Polish patients with PD, using the search terms 'Parkinson's disease, 'Polish', 'genetics', 'mutations', and 'variants'.

Results. In total, 73 publications were included in the review; 11 genes responsible for monogenic forms and 19 risk factor genes have been analysed in the Polish population. Pathogenic variants were reported in four monogenic genes (LRRK2, PRKN, PINK1, and SNCA). Eight genes were associated with PD risk in the Polish population (GBA, TFAM, NFE2L2, MMP12, HLA-DRA, COMT, MAOB, and DBH). Multiplex ligation-dependent probe amplification and Sanger sequencing in PRKN, PINK1, DJ1, LRRK2, and SNCA revealed SNCA duplication in a 43-year-old Polish patient with PD examined by movement disorder specialists.

Conclusion. Only a limited number of positive results have been reported in genes previously associated with PD in the Polish population. In the era of personalised medicine, it is important to report on genetic findings in specific populations.
\end{abstract}

Key words: genetics, Parkinson's disease, Polish population, SNCA duplication

(Neurol Neurochir Pol 2021; 55 (3): 241-252)

\section{Introduction}

Parkinson's disease (PD) is one of the most common neurodegenerative movement disorders worldwide, affecting people of all ethnic groups [1]. The cardinal motor features include tremor, rigidity, bradykinesia or akinesia, and postural instability [2-4]. The pathophysiology of this disease is based on degeneration of dopaminergic neurons in the substantia nigra [1]. The characteristic neuropathological feature is the presence of Lewy bodies composed of aggregated $\alpha$-synuclein fibrils. However, many different molecular pathways of dysfunction have been proposed leading to PD [1]. Diagnosis is usually based on clinical features, but radiological methods such as dopamine transporter scan and positron emission tomography are useful diagnostic tools $[5,6]$.
Multiple factors may be associated with the prevalence of PD. The frequency of PD and PD subtypes differ in different ethnic groups. One of the most common observations is that PD occurs much more frequently in Western populations. However, there are specific ethnic groups in Asia and Africa where PD is common [7]. The factors impacting upon disease prevalence also differ across populations [8,9]. One difference in prevalence may be associated with the most important risk factor for PD: age [10]. Western European ethnic groups are usually older than subgroups from low-income countries, so the prevalence of PD is higher. Also, diagnostic and therapeutic options are more available in high-income countries $[11,12]$. Furthermore, genetic background is characteristic for different ethnic groups [10]. Most PD cases are sporadic; however, about $15 \%$ are familial [1]. The genetic cause of PD

Address for correspondence: Zbigniew K. Wszolek, Department of Neurology, Mayo Clinic, 4500 San Pablo Rd, Jacksonville, FL 32224, USA,

e-mail: Wszolek.Zbigniew@mayo.edu 
is usually determined in patients with early-onset PD (EOPD) or in those with a positive family history. Many genetic loci associated with PD have been identified.

In the Online Mendelian Inheritance in Man (OMIM) database, 23 genes have been associated with monogenic forms of PD. The last genome-wide association study (GWAS) identified more risk genes than the 23 already in the OMIM database; $>90$ risk loci [13].

Poland is ethnically homogenous; the current population is 38 million and $97.1 \%$ declare Polish nationality. However, in the past, many different minority groups have lived in current Polish territories; the borders have changed many times, resulting in massive migrations of people. These factors have led to the presence of a unique genetic background in this country. Poland has a substantial older population and the occurrence of PD is increasing; approximately 75,000 cases were reported in 2016 [14].

Many genetic PD loci associated with different pathways have been studied in the Polish population. Patients have been recruited in five main PD centres in Poland (Supplementary Fig. 1).

The aim of this review was to summarise the genetic studies that have been conducted in Polish patients with PD. The electronic database, PubMed, was searched for articles published between January 1995 and June 2020 relating to studies that evaluated genetics in Polish patients with PD. Review articles and meta-analyses were also investigated, and their reference lists were examined for possible inclusion. Our search was limited to human studies. We used the following search terms: 'Parkinson's disease,' 'Polish', 'genetics,' 'mutations', and 'variants'. We also describe a new Polish patient with SNCA duplication. The blood specimen from this patient was collected with institutional review board approval, and informed consent was signed.

\section{Monogenic forms of PD}

In monogenic forms of $\mathrm{PD}$, the disease is inherited dominantly or recessively by mutation of a single gene. The monogenic forms of PD are responsible for about $30 \%$ of familial forms and 3-5\% of sporadic cases [15]. Several genes from this group have been reported in Polish populations (Tab. 1) [16-30].

\section{Autosomal recessive $\mathrm{PD}$ genes}

Many studies of monogenic PD forms in Polish populations have analysed the three most common autosomal recessive genes reported in EOPD: PRKN, PINK1, and DJ1 [16, 20, $23,24,31]$. Though typical age at onset for $P D$ is above 60 years, EOPD is defined in different ways. While the European Parkinson's Disease Association defines 'early' as age at onset younger than 40, the American Parkinson's Disease Association defines it as age at onset younger than 50. EOPD is reported in about $5 \%$ of patients [32]. Summaries of monogenic PD forms are provided in Table 1 and Figure 1.

\section{PRKN (OMIM 602544, PARK2)}

The $P R K N$ gene is associated with the autosomal recessive form of EOPD [33]. PRKN encodes the protein responsible for quality control of mitophagy. PRKN is an E3 ubiquitin ligase that participates in ubiquitin-proteasome interaction. Mutations in PRKN result in degradation of damaged mitochondria, leading to oxidative stress that can damage the substantia nigra dopaminergic cells [15]. According to published data, the mutations in PRKN are present in a large proportion of EOPD worldwide (up to $18 \%$ of patients) [15]. PRKN PD type is characterised by a broad range of clinical phenotypes, some atypical signs, but generally has early onset, slower progression, better response to levodopa, and often more severe drug-induced adverse effects [34]. Sometimes in the clinical phenotype in carriers, parkinsonism is not a dominant symptom [31].

Several studies have analysed PRKN in Polish populations. The first case-control study of 79 patients with EOPD (onset $<40$ years) and 204 controls revealed two patients with homozygous or compound heterozygous mutation and one with heterozygous mutation (3.8\%) [24]. A study of 150 patients with EOPD (onset $<45$ years) reported $P R K N$ mutations in 4.7\% [23]. Gaweda-Walerych et al. [20] identified only one heterozygous $P R K N$ deletion; however, from 344 patients with PD (171 EOPD), Ambroziak et al. [16] identified five compound heterozygous and three heterozygous mutations.

\section{PINK1 (OMIM 608309, PARK6)}

PINK1 (phosphatase and tensin homolog-induced putative kinase 1) is another common cause of early-onset parkinsonism worldwide. It was first described in a large Italian family and is the second most commonly identified mutation in patients with autosomal recessive EOPD [35]. PINK1 protein strongly cooperates with $P R K N$ in mitochondrial quality control to identify, label, and remove damaged organelles. PINK1 is responsible for ubiquitin phosphorylation at Ser65. The endogenous Ser65 phosphopeptide is only detected with PINK1 and together cause a decrease in mitochondrial membrane potential [27].

In the first Polish PINK1 genetic study, only four patients with EOPD (2.67\%) were carriers of PINK1 mutations (one homozygote) [23]. Another study analysed molecular characteristics of PINK1 p.Gln456Ter mutation present in two family members. This mutation can lead to a decrease in mRNA and loss of protein function $[29,36]$. One molecular study revealed that previously described PINK1 p.Ile368Asn cannot be stabilised on the outer mitochondrial membrane upon mitochondrial stress, and due to conformational changes in the active site, does not exert kinase activity towards ubiquitin [17]. In 748 Polish patients with PD, $0.94 \%$ were carriers of PINK1 p.Gly411Ser mutation, which increased PD risk via dominant-negative mechanism [27]. 
Table 1. Autosomal recessive and autosomal dominant inherited genes analysed in Polish populations

\begin{tabular}{|c|c|c|c|}
\hline Gene & $\begin{array}{l}\text { Chromosome } \\
\text { localisation }\end{array}$ & Results & Study group \\
\hline \multicolumn{4}{|c|}{ Autosomal recessive } \\
\hline \multirow[t]{4}{*}{ PRKN } & $6 q 26$ & $\begin{array}{l}2 \text { homozygotes/compound heterozygotes and } 1 \text { hetero- } \\
\text { zygote }\end{array}$ & 79 EOPD, age < 40 y [24] \\
\hline & & 5 compound heterozygotes, 2 heterozygotes & 150 EOPD, age < 45 y [23] \\
\hline & & 5 compound heterozygotes, 3 heterozygotes & 344 PD (171 EOPD, age < 45 y; 173 LOPD) [16] \\
\hline & & No pathogenic mutations & 104 EOPD, age $\leq 50$ y $[20]$ \\
\hline \multirow[t]{4}{*}{ PINK1 } & $1 p 36.12$ & 1 homozygote, 3 heterozygotes & 150 EOPD, age < 45 y [23] \\
\hline & & PINK1 p.GIn456Ter in both patients & 2 family members affected [29] \\
\hline & & PINK1 p.lle368Asn in both patients & 2 family members affected [17] \\
\hline & & $0.94 \%$ p.Gly411Ser PINK1 mutation carriers & 748 PD [27] \\
\hline DJ1 & $1 p 36.23$ & No pathogenic mutations & 150 EOPD, age < 45 y [23] \\
\hline \multicolumn{4}{|c|}{ Autosomal dominant } \\
\hline \multirow[t]{2}{*}{ LRRK2 } & $12 q 12$ & 1 G2019S heterozygote & 100 sporadic PD [22] \\
\hline & & No pathogenic variants & 174 sporadic PD [18] \\
\hline \multirow[t]{2}{*}{ SNCA } & $4 q 22.1$ & $\begin{array}{l}\text { No p.Ala30Pro, p.Glu46Lys, p.Ala53Thr, or multiplication } \\
\text { p.Ala18Thr in } 1 \text { patient, p.Ala29Ser in } 1 \text { patient }\end{array}$ & 629 PD [21] \\
\hline & & SNCA duplication in patient with EOPD ${ }^{a}$ & 1 sporadic PD $^{\mathrm{a}}$ \\
\hline VPS35 & $16 q 11.2$ & No pathogenic mutations & 346 PD [30] \\
\hline DNAJC13 & $3 q 22.1$ & No pathogenic mutations & 702 PD (9.23\% positive family history) [25] \\
\hline $\mathrm{CHCHD2}$ & $7 p 11.2$ & No pathogenic mutation & 394 PD [26] \\
\hline EIF4G1 & $3 q 27.1$ & $\begin{array}{l}\text { p.Ala502Val in } 1 \text { patient (variant of uncertain pathogeni- } \\
\text { city) }\end{array}$ & 397 PD [19] \\
\hline HTRA2 & $2 \mathrm{p} 13.1$ & No pathogenic mutations & 101 PD [28] \\
\hline
\end{tabular}

EOPD — early-onset PD; LOPD — late-onset PD; PD — Parkinson's disease; ${ }^{2}$ New patient

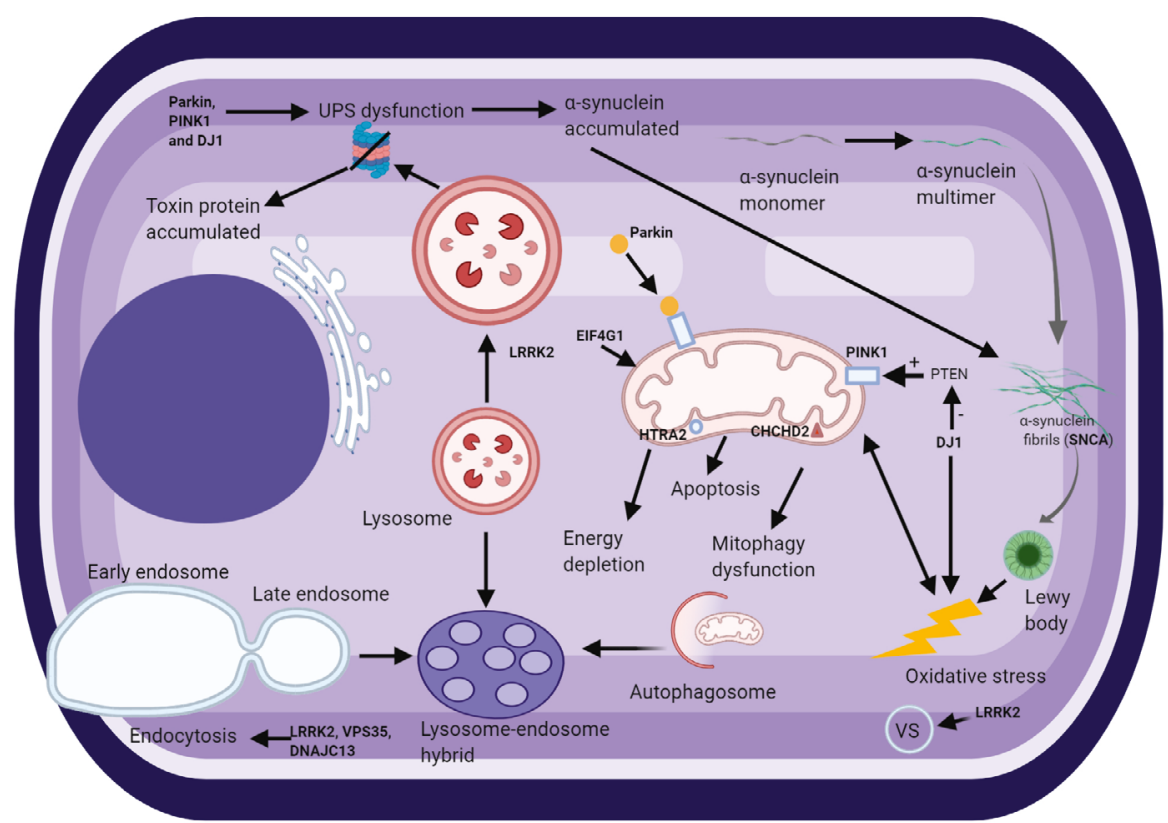

Figure 1. Main pathways associated with Parkinson's disease pathophysiology explored in Polish patients. Bold indicates protein encoding by genes responsible for monogenic forms of PD

ER - endoplasmic reticulum; SV - synaptic vesicle; UPS - ubiquitin-proteasome system 


\section{DJ1 (OMIM 602533, PARK7)}

The third most commonly reported EOPD gene is DJ1; however, it is much rarer than PRKN and PINK1. It has been reported in only a few populations [37]. As with $P R K N$ and PINK1, DJ1 participates in mitochondrial quality control. DJ1 increases the expression of two mitochondrial proteins, UCP4 and UCP5, which decrease mitochondrial membrane potential, reduce reactive oxygen species production, improve mitochondrial functions, and protect the neuronal cells [38]. No DJ1 variants have been reported in Polish populations [23].

\section{Autosomal dominant PD genes}

Autosomal dominant inherited genes generally cause medium-onset to late-onset parkinsonism or PD, with few or no additional symptoms. The characteristic feature is incomplete penetrance of these genes [1].

\section{LRRK2 (OMIM 600907, PARK8)}

$L R R K 2$, a large $(7,584 \mathrm{bp})$ gene that encodes leucine-rich repeat kinase 2 , is the most common genetic cause of PD. The main purpose of this protein remains unknown, but it may involve such cellular functions as neurite outgrowth, cytoskeletal maintenance, vesicle trafficking, autophagic protein degradation, and the immune system. The well-established association with autosomal dominant $P D$ had six variants. The first families identified with mutation in LRRK2 were in Japan and the US $[39,40]$. The most commonly reported LRRK2 mutation is the p.Gly2019Ser variant, detected in 30\% and 13\% of Arab-Berber and Ashkenazi Jewish familial cases of PD, respectively [41, 42]. It has also been reported in up to $6 \%$ of familial and $2 \%$ of sporadic European PD cases [43]; however, in the Polish population it is rather rare. A study screening for $L R R K 2$ variants in a European population only found them in one Polish family [22], while another study performed in 174 Polish patients did not reveal any pathogenic variants in this gene [18].

\section{VPS35 (OMIM 601501, PARK17)}

VPS35 (vacuolar protein sorting $35 \mathrm{homolog}$ ) is a rare cause of autosomal dominant PD. The first reported variant, p.Asp620Asn, was described in Swiss and Austrian families with late-onset PD [30,44]. The encoding protein is responsible for transmembrane receptor recycling and protein transport between the endoplasmic reticulum and the trans Golgi network. The functional protein cooperates with two other proteins, VPS26 and VPS29, to create a highly conservative, active complex. All three genes were analysed in 356 Polish patients with PD, but no variants in VPS26 and VPS29 were found [45]. The original paper describing a VPS35 variant in a PD family also included analysis of 346 patients with PD and did not reveal any other pathogenic variants [30].

\section{SNCA (OMIM 163890, PARK1)}

SNCA mutation was first described in mixed Greco-Italian and Greek families [46]. Initially, point mutations were reported, then multiplications [47]. The clinical phenotype is consistent with late-onset PD with a positive family history and is associated with a good response to levodopa treatment. Occasionally, patients have multiple system atrophy phenotype. Fifty-nine families with SNCA duplications have been described worldwide [48]. In some patients with duplications, there is no family history and the phenotype is variable. Patients with triplications usually have earlier age at onset and more severe clinical symptoms [49]. From 629 Polish probands, two sporadic cases with variants, p.Ala18Thr and p.Ala29Ser, were reported, but P.Ala30Pro, p.Glu46Lys, and p.Ala53Thr and multiplication variants were not discovered [21]. The clinical phenotype was characterised by a good response to levodopa, at least at the beginning of the disease. Post mortem of the patient with p.Ala29Ser mutation revealed Lewy bodies and neuritis [21].

We recently identified the first Polish patient with SNCA duplication. A 43-year-old right-handed man was referred to the neurology clinic. He had been suffering from right hand tremor for two years. Neurological examination revealed hypomimia, slow speech with dysarthria, bradykinesia, rigidity, and rest tremor on the right side. He reported anosmia and mild drooling, but denied any sleep disturbances. Family history was negative for PD. The patient was diagnosed with PD and initial levodopa treatment ( $200 \mathrm{mg}$ daily) was implemented, with good response. Because of the younger age at onset $(<50)$, multiplex ligation-dependent probe amplification in PRKN, PINK1, DJ1, $L R R K 2$, and $S N C A$ and Sanger sequencing in $P R K N$ were performed, revealing a heterozygous SNCA duplication (Fig. 2).

\section{Candidate familial PD genes}

Additional genes have been identified as possible causes of PD. Analyses of autosomal-dominant PD families initially identified DNAJC13, CHCHD2, EIF4G1, LRP10, NUS1, and HTRA2 as causative genes; however, data from the case-control study did not support this observation [50]. These genes were also analysed in Polish populations (Tab. 1).

\section{DNAJC13 (OMIM 616361, PARK21)}

The first variant in this gene was observed in a Dutch-German-Russian Mennonite family [51]. DNAJC13 (DnaJ [Hsp40] homolog, subfamily C, member 13 protein) is associated with recycling and functioning of the lysosomal system. In a population of 702 Polish patients with PD with $9.23 \%$ positive family history, no pathogenic variants were observed [25].

\section{CHCHD2 (OMIM 616710, PARK22)}

Heterozygous mutations in CHCHD2 (coiled-coil-helix-coiled-coil-helix domain containing 2) were identified first in Japanese families with autosomal dominant patterns of inheritance of PD. The protein is responsible for cytochrome c oxidase activity by acting as a transcription factor to regulate cytochrome $\mathrm{c}$ oxidase expression, thereby facilitating mitochondrial electron transport chain flux under low oxygen 


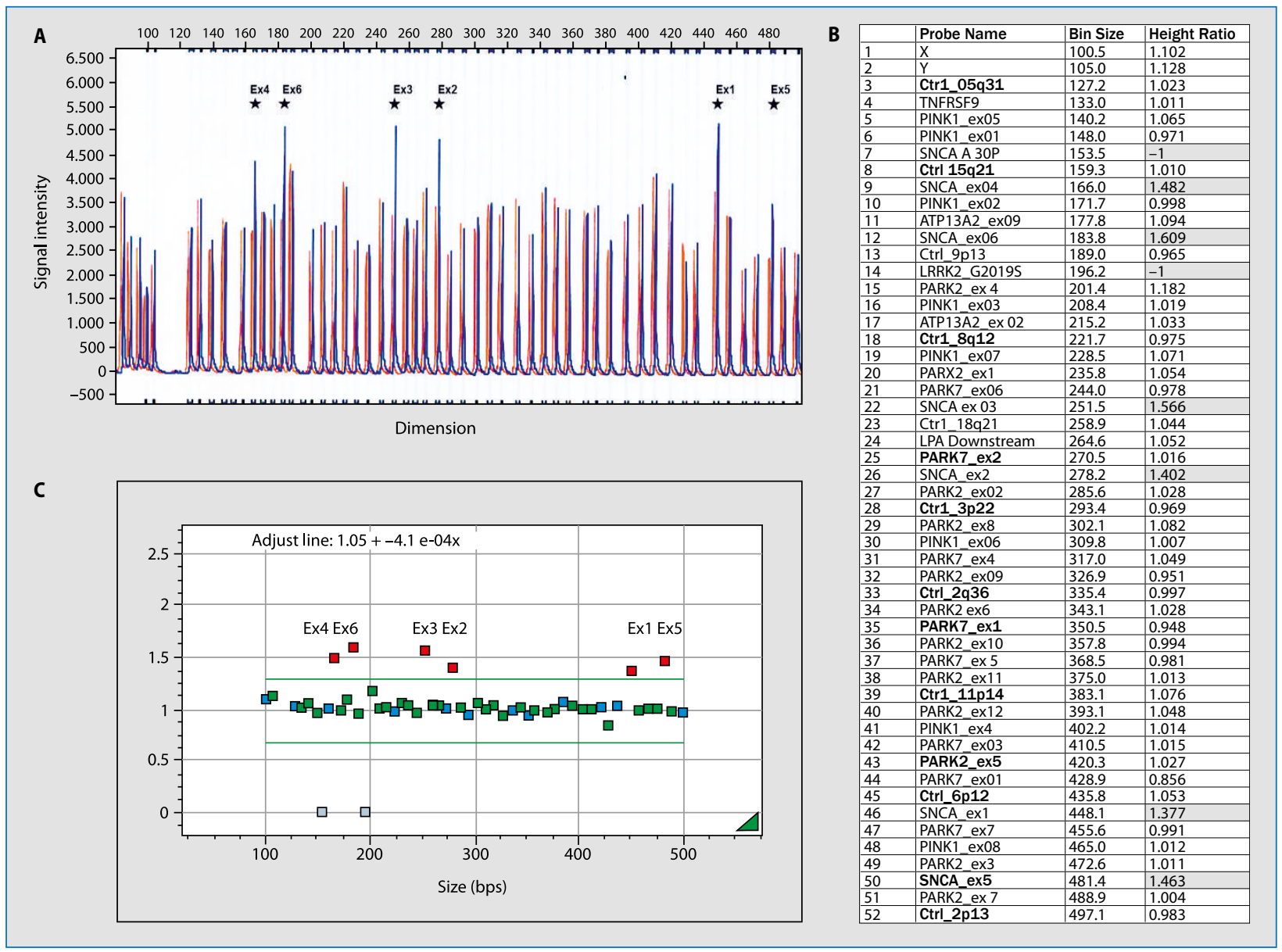

Figure 2. Detection of the SNCA gene duplication in EOPD patient with multiplex ligation-dependent probe amplification (MLPA) method. Reaction was performed with SALSA MLPA Probe mixes P051 (MRC Holland). Dosage analysis was performed with GeneMarker Software v.2.7.0 (SoftGenetics, LLC). A. Trace comparison - overdosage of all SNCA exons of patient's sample in relation to control. This panel shows the differences in peak height between patient's sample (blue) and control (red) for all SNCA exons. B. Report table - reporting peak ratio for all probes, duplication of SNCA exons (high ratio > 1.3) are indicated in positions 9,12, 22,24, 26,46 and 50. C. Ratio plot - visualization of the peak ratios. Normal relative probe signals are between the green lines $(0.7-1.3)$, and are depicted in green. Aberrant relative probe signals are depicted in red

conditions and inhibiting mitochondria-mediated apoptosis. In a study of 394 Polish patients with PD, there were no definite pathogenic variants in this gene [26].

\section{EIF4G1 (OMIM 614251, PARK18)}

EIF4G1 encodes the protein, eIF4F, a component of the translation initiation complex. In a cohort of 397 Polish patients with PD, p.Ala502Val variant with unknown pathogenicity was identified in a single case [19]. However, further analysis of this locus did not support its pathogenicity [52].

\section{HTRA2 (OMIM 610297, PARK13)}

The Htra2 protein, a serine protease located in mitochondria, is responsible for apoptosis, especially during stress conditions. This protein is also an element of Lewy bodies. HTRA2 was first reported in German familial and sporadic PD cases [53], but in 101 Polish patients with PD, no pathogenic variants were reported [28].

\section{Risk factor genes}

In addition to the genes responsible for familial forms of $\mathrm{PD}$ listed in the OMIM database, other genetic loci have been identified that increase the risk of PD occurrence. Some genes can be included as both monogenic and risk factor genes. Most mutations of SNCA are responsible for monogenic forms of PD, but some polymorphisms (e.g. rs356219) are risk factors for PD [54]. The last GWAS revealed about 90 genomic regions that can be associated with PD prevalence [13]. However, risk factor genes were analysed in a population of less than 1,000 Polish patients with PD, and so the study was underpowered [55]. While GWAS PD studies are conducted mainly in European populations, Polish patients with PD are not often included in the analysis [13].

\section{GBA}

$G B A$ encoding glucocerebrosidase is one of the first risk factors described in PD. The encoding protein is a lysosomal hydrolase located in the lysosomal membrane and is involved 
in the degradation of a sphingolipid glucocerebroside. $\mathrm{Mu}$ tations in both alleles are responsible for Gaucher's disease, which is characterised by glucocerebroside accumulation and secondary macrophage accumulation [56]. Heterozygous carriers of $G B A$ variants had increased risk of $P D$, and the highest prevalence of $G B A$ mutations occurred in Ashkenazi Jewish patients. GBA variants were found in $19 \%$ of patients with PD and 3\% of the general population [56]. In the first study conducted in a Polish population, $4.07 \%$ of GBA carriers were reported in a group of 270 non-demented patients with PD [57]. The second study revealed 16 carriers (11.6\%) among 138 Polish patients with PD [58]. It is known that dementia occurs more often in GBA mutation carriers $(60.0 \%$ vs. $19.6 \%)$ [58].

\section{APOE}

Apolipoprotein E plays a key role in lipid metabolism. $A P O E$ is considered one of the most important genetic risk factors for Alzheimer's disease (AD). Three common polymorphisms $(\varepsilon 2, \varepsilon 3$, and $\varepsilon 4)$ and six genotypes $(\varepsilon 2 / \varepsilon 2, \varepsilon 3 / \varepsilon 3$, $\varepsilon 4 / \varepsilon 4, \varepsilon 2 / \varepsilon 3, \varepsilon 2 / \varepsilon 4, \varepsilon 3 / \varepsilon 4)$ have been identified in $A P O E$, and $\varepsilon 3$ is the most common allele. The potential impact of these variants was studied in the context of the occurrence of dementia in PD, rather than disease prevalence [59]. In a Polish population with $\mathrm{PD}$, Pierzchlinska et al. [60] revealed no statistically significant correlation between $A P O E$ genotypes and dementia. Another study of 407 Polish patients with PD found no statistically significant differences in the distribution of $A P O E$ genotypes [60].

\section{Other genetic analysis in Poland}

We found other studies of Polish populations that do not fit into the gene groups described above. They describe mutations in mitochondrial DNA and genes associated with the immune system or with dopamine metabolism. All pathways analysed in Polish populations are set out in Table 2 [57, 58, 60-78].

Mitochondrial dysfunction has been implicated in PD pathogenesis [79]. The mutations causing mitochondrial dysfunction in nuclear DNA also risk variants in mitochondrial DNA [70]. Some changes in mitochondrial DNA may modify risk of PD. Mitochondrial transcription factor A (TFAM) has been shown to decrease reactive oxygen species [80]. The intronic variant rs 2306604 increased risk of PD in an analysis of 326 patients with PD [67]. Mitochondrial DNA can be divided into haplogroups, restricted to particular populations and geographical areas.

Multiple European haplogroups, including J, K, U, and some super-haplogroups (e.g. UK and JT), have been associated with a reduced risk of PD [70]. This observation was also made in a Polish population [81]. Haplogroup J was associated with a lower PD risk in men. Subcluster K1a was more prevalent in healthy controls, while K1c was more frequent in patients with $\mathrm{PD}(p=0.025$ and $p=0.011$, respectively).
Furthermore, the sublineages (U4 + U5a1 + K + J1c + J2) previously proposed to partially uncouple oxidative phosphorylation decrease PD risk $(p=0.027)$ [81]. No impact of TOMM40 on disease occurrence was observed in $407 \mathrm{PD}$ patients [71].

Oxidative stress is one of the best-known potential pathomechanisms of PD. NFE2L2 encoding nuclear factorerythroid 2-related factor 2 is responsible for regulation of the expression of many antioxidant pathway genes in the so-called phase II response. In a Polish case-control study, NFE2L2 haplotypes decreased the risk of PD for heterozygous and homozygous carriers [78]. Matrix metalloproteinases are huge families of endopeptidases important in inflammation. One of these families is macrophage metalloelastase (MMP12), first identified as an elastolytic metalloproteinase secreted by inflammatory macrophages [82]. In 241 patients with PD, rs652438 G allele genotypes of MMP12 decreased the risk of the disease [65].

One of the pathways previously associated with PD and strictly connected with oxidative stress is the immune system. In an analysis of the human leukocyte antigen region polymorphism HLA-DRA rs3129882 in 343 Polish patients with PD, the recessive model of GG genotype was observed to be protective [73]. In another case-control study (341 patients with PD and 315 controls), polymorphisms in $I L-10(-1082 \mathrm{G}>\mathrm{A}$ and $-592 \mathrm{C}$ $>$ A) were not risk factors for sporadic PD [63]. Although semaphorins are the proteins responsible for regulation of the immune system and tumour progression, rs7702187 SNP in SEMA5A was not a marker of PD risk in 235 Polish patients with PD [64]. The triggering receptor expressed on myeloid cells 2 (TREM2) is a member of the innate immune receptor of the TREM family. It is found on activated macrophages, immature dendritic cells, osteoclasts and microglia. While the TREM2 p.Arg47His (rs75932628) variant has been associated with increased risk of PD in a Polish study, this variant was rare in patients with $\mathrm{PD}$ and no variants were reported in controls [74].

A few studies have been conducted on the variants encoding enzymes associated with dopamine metabolism pathway $[61,62,75,83]$. Lack of dopamine in synapses is a main clinical indication of PD. Because levodopa is a basic treatment for PD, polymorphisms in these enzymes may impact upon response to this treatment. A couple of studies in Polish patients have analysed genes encoding enzymes associated with dopamine metabolism [61, 62]. Catechol-O-methyltransferase (COMT) and monoamine oxidase $\mathrm{B}(\mathrm{MAOB})$ are involved in dopamine degradation in synapses. A study of 210 Polish patients with PD found a significantly lower frequency of the COMT LL genotype responsible for high enzyme activity [61]. The combined haplotype of the MAOB $\mathrm{G}(\mathrm{G} / \mathrm{G})$ and COMT HL genotypes showed a four-fold increase $(p<0.05)$ in the risk of PD in women [61]. Bialecka et al. [62] analysed the impact of these polymorphisms on response to treatment. Their five-year observational study of 95 Polish patients with PD analysed 
Table 2. Genetic risk factors associated with PD analysed in Polish populations

\begin{tabular}{|c|c|c|}
\hline Gene & Mechanism & Results \\
\hline$A P O E$ & Responsible for lipid metabolism; pathological aggregation of proteins & No impact on PD and PDD occurrence [60] \\
\hline GBA & $\begin{array}{l}\text { Lysosomal hydrolase responsible for degradation of a sphingolipid } \\
\text { glucocerebroside }\end{array}$ & $\begin{array}{l}2 \text { studies: } \\
-4.07 \% \text { in } 270 \text { non-demented patients with PD [57] } \\
-11.6 \% \text { in } 138 \text { patients with PD [58] }\end{array}$ \\
\hline \multicolumn{3}{|c|}{ Mitochondrial dysfunction } \\
\hline TFAM & Mitochondrial DNA transcription factor & $\begin{array}{l}\text { Intronic variant rs } 2306604 \text { increased risk of } \mathrm{PD} \text { in analysis in } \\
326 \text { patients with } \mathrm{PD}(\mathrm{OR}, 1.789 ; 95 \% \mathrm{Cl}, 1.162-2.755 \\
p=0.008)[67]\end{array}$ \\
\hline TOMM40 & Translocase of the outer mitochondrial membrane 40 homolog & No impact on PD occurrence [71] \\
\hline $\begin{array}{l}\text { Haplo- } \\
\text { group J }\end{array}$ & Mitochondrial DNA & $\begin{array}{l}\text { Associated with lower PD risk in men }(\mathrm{OR}, 0.19 ; 95 \% \mathrm{Cl} \text {, } \\
0.069-0.530 ; p=0.0014)[70]\end{array}$ \\
\hline \multicolumn{3}{|c|}{ Oxidative stress and immune system } \\
\hline NFE2L2 & Regulation of expression of many antioxidant pathway genes & $\begin{array}{l}\text { NFE2L2 haplotypes decrease risk of PD-heterozygous } \\
(\mathrm{OR}, 0.4 ; 95 \% \mathrm{Cl}, 0.3-0.6 ; p<0.001) \text {, homozygous (OR, } \\
0.2 ; 95 \% \mathrm{Cl}, 0.1-0.4 ; p<0.001)[78]\end{array}$ \\
\hline MMP12 & $\begin{array}{l}\text { Matrix metalloproteinase secreted by inflammatory macrophages, } \\
\text { responsible for inflammatory reaction }\end{array}$ & $\begin{array}{l}\text { rs652438G allele genotypes decrease risk of disease } \\
(\mathrm{OR}, 0.47 ; 95 \% \mathrm{Cl}, 0.26-0.85 ; p=.013)[65]\end{array}$ \\
\hline$H L A-D R A$ & Human leukocyte antigen & $\begin{array}{l}\text { rs3129882 GG genotype protective for PD occurrence } \\
(\mathrm{OR}, 0.67 ; p=0.04)[73]\end{array}$ \\
\hline IL-10 & $\begin{array}{l}\text { Modulatory effects against proinflammatory cytokines, especially INF- } \gamma \\
\text { and TNF- } a\end{array}$ & No impact on PD occurrence [63] \\
\hline SEMA5A & Regulation of immune system and tumour progression & No impact on PD occurrence [64] \\
\hline TREM2 & $\begin{array}{l}\text { Found on activated macrophages, immature dendritic cells, osteoclasts, } \\
\text { and microglia }\end{array}$ & No impact on PD occurrence [74] \\
\hline \multicolumn{3}{|c|}{ Dopamine and other neurotransmitter metabolism } \\
\hline COMT & Catecholo-O-metylotransferase, responsible for dopamine metabolism & Lower frequency of COMT LL in PD [61] \\
\hline \multirow[t]{2}{*}{$M A O-B$} & \multirow[t]{2}{*}{ Monoamine oxidase $B$ responsible for dopamine metabolism } & $\begin{array}{l}\text { MAOB G }(\mathrm{G} / \mathrm{G}) \text { and } C O M T \mathrm{HL} \text { genotype } \rightarrow \text { fourfold increased } \\
\text { risk of PD in women }(p<0.05)\end{array}$ \\
\hline & & No impact on response to treatment [62] \\
\hline $\mathrm{DBH}$ & Noradrenaline synthesis from dopamine in plasma & rs1611115 was observed more often $(\mathrm{OR}, 2.01 ; p=0.01)[75]$ \\
\hline MDR1 & Responsible for regulating environmental xenobiotics concentration & No impact on PD occurrence [77] \\
\hline \multicolumn{3}{|c|}{ Pathways associated with other neurodegenerative disorders } \\
\hline STH & Impact on AD pathogenesis & No impact on PD occurrence [72] \\
\hline GRN & Impact on FTD occurrence & No impact on PD occurrence [68] \\
\hline MAPT & Microtubule-associated protein & No impact on PD occurrence [69] \\
\hline CALB1 & L-type voltage-operated calcium channels & No impact on PD occurrence [76] \\
\hline DAPK1 & $\begin{array}{l}\mathrm{Ca} 2+/ \text { calmodulin-dependent serine/threonine kinase that plays } \\
\text { a proapoptotic role in programmed cell death cascade }\end{array}$ & No impact on PD occurrence [66] \\
\hline
\end{tabular}

the presence of COMT $\mathrm{L}$ and $M A O B \mathrm{G}$ polymorphisms in two study groups: those receiving less than $500 \mathrm{mg} /$ day of levodopa, and those receiving $500 \mathrm{mg} /$ day or more during the observational period. No statistical differences were observed between these groups [62]. Another study examined differences in polymorphism distribution in dopamine B-hydroxylase $(D B H)$, responsible for noradrenaline synthesis from dopamine in plasma [75]. In a study of 224 Polish patients, $D B H-1021 \mathrm{C}>\mathrm{T}$; rs 1611115 was observed more often in the study group than in controls [75]. Michalowska et al. analysed the occurrence of polymorphisms in genes associated with dopaminergic metabolism and their impact on risk of PD and motor levodopa-induced adverse effects. They found that rs6265 BDNF (p.Val66Met) was associated with risk of PD. Additionally, they observed a synergic effect of rs6265 BDNF (p.Val66Met), rs397595 DAT (SLC6A3), and rs4680 COMT (p.Val158Met) polymorphisms on the occurrence of motor levodopa-induced adverse effects [83]. In a study of 158 patients with PD and 139 controls, Tan et al. [77] analysed seven SNPs from MDR1 responsible for regulating environmental xenobiotics, but found no significant differences between the two groups. 
The correlation of eight SNPs localised in the chromosomal region 2q24.3, previously associated with PD risk, was analysed; however, a study of 713 Polish patients revealed no association with PD risk [84]. The saitonin p.Gln7Arg polymorphism previously associated with $\mathrm{AD}$ was analysed in 100 patients with PD, but no association with disease occurrence was observed [72]. An SNP in the progranulin gene (GRN; $3^{\prime} \mathrm{UTR}+78 \mathrm{C}>\mathrm{T}$; rs5848) associated with frontotemporal dementia was not found to be a risk factor for PD in 364 Polish patients [68]. Microtubule-associated protein $\tau$ was previously reported to be associated with $A D$ and frontotemporal dementia; however, a study of 832 Polish patients with PD found no impact on disease presence with MAPT p.Ala152Thr variant [69]. Death-associated protein kinase 1 , previously reported in $\mathrm{AD}$, was also not observed in patients with PD patients [66]. Calbindin belongs to L-type voltage-operated calcium channels. It has been reported that rs1805874 SNP may increase the risk of PD in Japanese patients [85]; however, this observation was not confirmed in Polish or other European populations (Tab. 2) [76]. Locus 5q23 (D5S1462 and D5S2501) was identified in two large Polish families with levodopa responsive parkinsonism [86, 87].

\section{Clinical implications}

Our report summarises the prevalence of $\mathrm{PD}$ genetic factors in the Polish population, and presents the first case of SNCA duplication in this population. Many genes responsible for both familial forms of PD and increased risk of disease have been established in the Polish population. Data indicates that PD genes reported in other countries are rarely observed in this population.

The diagnosis of PD is still based on clinical examination. Detailed genetic characteristics of specific populations may lead to the discovery of new PD biomarkers [86]. With the increasing availability of personalised medicine, the number of clinical trials calling for specific mutation carriers will increase. Currently, there is an ongoing phase I clinical trial for LRRK2 p.Gly2019Ser mutation carriers. Antisense oligonucleotide BIIB094 binds to LRRK2 mRNA and causes its degradation (NCT03976349). Another trial analysed DNL201 particle inhibition of the LRRK2 protein (NCT03710707) [87]. The most explored gene in the context of clinical trials is GBA. There are six ongoing clinical trials (three phase 1 and three phase 2) with different mechanisms, including glucocerebrosidase activators, glucosylceramide synthases inhibitors, and adeno-associated virus gene therapy $[87,88]$. In 2019, the Michael J. Fox Foundation announced funding for development for PRKN and PINK1 [89]. In the 2019, the Michael J. Fox Foundation announced funding for development for PRKN and PINK1 targeted therapy.

\section{Future perspectives}

Many PD genes have been extensively screened in the Polish population. The frequency of variants in known genes is low. However, some methodological approaches (GWAS or clinical exomes analysis) have not been conducted yet. Furthermore, there are new sequencing methods, such as long-read sequencing, which can directly sequence single molecules of DNA in real time, often without the need for amplification. This direct sequencing approach enables the production of reads that are considerably longer than those resulting from classical short-read sequencing, allowing the sequencing of parts of the genome that are yet to be discovered. Long-read sequencing will facilitate better genetic characterisation of all patients with PD.

Acknowledgments: Mayo Clinic is an American Parkinson's Disease Association (APDA) Information and Referral Centre and APDA Centre for Advanced Research, as well as a Lewy Body Dementia Association Research Centre of Excellence. This study was supported financially as part of the research grant from the National Science Centre in Poland (grant number: 2017/01/X/NZ4/01450).

Conflict of interest: Dr Milanowski is supported by the Polish National Agency for Academic Exchange Iwanowska's Fellowship PPN/IWA/2018/1/00006/U/00001/01, the APDA, and the Haworth Family Professorship in Neurodegenerative Diseases Fund. Dr Ross is supported by the National Institutes of Health (NIH; R01 NS78086; U54 NS100693; U54 NS110435), the US Department of Defense (W81XWH-17-1-0249), the Little Family Foundation, the Mayo Clinic Functional Genomics of LBD Programme, the Mayo Clinic Centre for Individualised Medicine, and the Michael J. Fox Foundation. Dr Wszolek is partially supported by the Mayo Clinic Centre for Regenerative Medicine, gifts from the Sol Goldman Charitable Trust and the Donald G. and Jodi P. Heeringa Family, the Haworth Family Professorship in Neurodegenerative Diseases Fund, and the Albertson Parkinson's Research Foundation. He serves as PI or Co-PI on grants from Biogen, Inc (228PD201) and Biohaven Pharmaceuticals, Inc (BHV4157-206 and BHV3241-301). He serves as PI of the Mayo Clinic APDA Information and Referral Centre, and as Co-PI of the Mayo Clinic APDA Centre for Advanced Research.

\section{References}

1. Balestrino R, Schapira A. Parkinson disease. European Journal of Neurology. 2019; 27(1): 27-42, doi: 10.1111/ene.14108.

2. Yoon WT. Comparison of dystonia between Parkinson's disease and atypical parkinsonism: The clinical usefulness of dystonia distribution and characteristics in the differential diagnosis of parkinsonism. Neurol Neurochir Pol. 2018; 52(1): 48-53, doi: 10.1016/j. pjnns.2017.11.004, indexed in Pubmed: 29196058.

3. Siuda J, Boczarska-Jedynak M, Budrewicz S, et al. Validation of the Polish version of the Movement Disorder Society-Unified Parkinson's Disease Rating Scale (MDS-UPDRS). Neurol Neurochir Pol. 2020; 54(5): 416425, doi: 10.5603/PJNNS.a2020.0049, indexed in Pubmed: 32639019.

4. Tipton PW, Uitti RJ, Cheshire WP. ,Falling off' the dopamine wagon. Neurol Neurochir Pol. 2019; 53(5): 390-391, doi: 10.5603/PJNNS. a2019.0048, indexed in Pubmed: 31657446. 
5. Barc K, Kuźma-Kozakiewicz M. Positron emission tomography neuroimaging in neurodegenerative diseases: Alzheimer's disease, Parkinson's disease, and amyotrophic lateral sclerosis. Neurol Neurochir Pol. 2019; 53(2): 99-112, doi: 10.5603/PJNNS.a2019.0013, indexed in Pubmed: 30855701.

6. Gajos A, Dąbrowski J, Bieńkiewicz M, et al. Should non-movement specialists refer patients for SPECT-DaTSCAN? Neurol Neurochir Pol. 2019; 53(2): 138-143, doi: 10.5603/PJNNS.a2019.0011, indexed in Pubmed: 30855703.

7. Pringsheim T, Jette N, Frolkis A, et al. The prevalence of Parkinson's disease: a systematic review and meta-analysis. Mov Disord. 2014; 29(13): 1583-1590, doi: 10.1002/mds.25945, indexed in Pubmed: 24976103.

8. Chan JCN, Malik V, Jia W, et al. Diabetes in Asia: epidemiology, risk factors, and pathophysiology. JAMA. 2009; 301(20): 2129-2140, doi: 10.1001/jama.2009.726, indexed in Pubmed: 19470990.

9. Jost WH, Altmann C, Fiesel T, et al. Influence of levodopa on orthostatic hypotension in Parkinson's Disease. Neurol Neurochir Pol. 2020; 54(2): 200-203, doi: 10.5603/PJNNS.a2020.0019, indexed in Pubmed: 32219811.

10. Sauerbier A, Aris A, Lim EeW, et al. Impact of ethnicity on the natural history of Parkinson disease. Med J Aust. 2018; 208(9): 410-414, doi: 10.5694/mja17.01074, indexed in Pubmed: 29764354.

11. Deutschländer AB. Treatment with istradefylline for postural abnormalities in Parkinson's disease. Neurol Neurochir Pol. 2019; 53(4): 239 241, doi: 10.5603/PJNNS.2019.0038, indexed in Pubmed: 31469906.

12. Szlufik S, Przybyszewski A, Dutkiewicz J, et al. Evaluating reflexive saccades and UDPRS as markers of Deep Brain Stimulation and Best Medical Treatment improvements in Parkinson's disease patients: a prospective controlled study. Neurol Neurochir Pol. 2019; 53(5): 341-347, doi: 10.5603/PJNNS.a2019.0045, indexed in Pubmed: 31621890.

13. Nalls MA, Blauwendraat C, Vallerga $C L$, et al. 23andMe Research Team, System Genomics of Parkinson's Disease Consortium, International Parkinson's Disease Genomics Consortium. Identification of novel risk loci, causal insights, and heritable risk for Parkinson's disease: a meta-analysis of genome-wide association studies. Lancet Neurol. 2019; 18(12): 1091-1102, doi: 10.1016/S1474-4422(19)30320-5, indexed in Pubmed: 31701892.

14. GBD 2016 Neurology Collaborators, GBD 2016 Parkinson's Disease Collaborators. Global, regional, and national burden of Parkinson's disease, 1990-2016: a systematic analysis for the Global Burden of Disease Study 2016. Lancet Neurol. 2018; 17(11): 939-953, doi: 10.1016/S1474-4422(18)30295-3, indexed in Pubmed: 30287051.

15. Domingo A, Klein C. Genetics of Parkinson disease. Neurogenetics, Part I. 2018: 211-227, doi: 10.1016/b978-0-444-63233-3.00014-2.

16. Ambroziak W, Koziorowski D, Duszyc $K$, et al. Genomic instability in the PARK2 locus is associated with Parkinson's disease. J Appl Genet. 2015; 56(4): 451-461, doi: 10.1007/s13353-015-0282-9, indexed in Pubmed: 25833766.

17. Ando M, Fiesel FC, Hudec R, et al. The PINK1 p.I368N mutation affects protein stability and ubiquitin kinase activity. Mol Neurodegener. 2017; 12(1): 32, doi: 10.1186/s13024-017-0174-z, indexed in Pubmed: 28438176.

18. Bialecka M, Hui S, Klodowska-Duda G, et al. Analysis of LRRK2 G2019S and I2020T mutations in Parkinson's disease. Neuroscience Letters. 2005; 390(1): 1-3, doi: 10.1016/j.neulet.2005.07.045.

19. Chartier-Harlin MC, Dachsel JC, Vilariño-Güell C, et al. Translation initiator EIF4G1 mutations in familial Parkinson disease. Am J Hum
Genet. 2011; 89(3): 398-406, doi: 10.1016/j.ajhg.2011.08.009, indexed in Pubmed: 21907011.

20. Gaweda-Walerych K, Safranow K, Jasinska-Myga B, et al. PARK2 variability in Polish Parkinson's disease patients-interaction with mitochondrial haplogroups. Parkinsonism Relat Disord. 2012; 18(5): 520-524, doi: 10.1016/j.parkreldis.2012.01.021, indexed in Pubmed: 22361577.

21. Hoffman-Zacharska D, Koziorowski D, Ross OA, et al. Novel A18T and pA29S substitutions in $\alpha$-synuclein may be associated with sporadic Parkinson's disease. Parkinsonism Relat Disord. 2013; 19(11): 1057-1060, doi: 10.1016/j.parkreldis.2013.07.011, indexed in Pubmed: 23916651.

22. Kachergus J, Mata IF, Hulihan M, et al. Identification of a novel LRRK2 mutation linked to autosomal dominant parkinsonism: evidence of a common founder across European populations. Am J Hum Genet. 2005; 76(4): 672-680, doi: 10.1086/429256, indexed in Pubmed: 15726496.

23. Koziorowski D, Hoffman-Zacharska D, Sławek J, et al. Incidence of mutations in the PARK2, PINK1, PARK7 genes in Polish early-onset Parkinson disease patients. Neurol Neurochir Pol. 2013; 47(4): 319-324, doi: 10.5114/ninp.2013.36756, indexed in Pubmed: 23986421.

24. Koziorowski D, Hoffman-Zacharska D, Sławek J, et al. Low frequency of the PARK2 gene mutations in Polish patients with the early-onset form of Parkinson disease. Parkinsonism Relat Disord. 2010; 16(2): 136-138, doi: 10.1016/j.parkreldis.2009.06.010, indexed in Pubmed: 19628420.

25. Lorenzo-Betancor 0, Ogaki K, Soto-Ortolaza Al, et al. DNAJC13 p.Asn855Ser mutation screening in Parkinson's disease and pathologically confirmed Lewy body disease patients. Eur J Neurol. 2015; 22(9): 1323-1325, doi: 10.1111/ene.12770, indexed in Pubmed: 26278106.

26. Ogaki K, Koga S, Heckman MG, et al. Mitochondrial targeting sequence variants of the CHCHD2 gene are a risk for Lewy body disorders. Neurology. 2015; 85(23): 2016-2025, doi: 10.1212/ WNL.0000000000002170, indexed in Pubmed: 26561290.

27. Puschmann A, Fiesel FC, Caulfield TR, et al. Heterozygous PINK1 p.G411S increases risk of Parkinson's disease via a dominant-negative mechanism. Brain. 2017; 140(1): 98-117, doi: 10.1093/brain/ aww261, indexed in Pubmed: 27807026.

28. Ross OA, Soto Al, Vilariño-Güell C, et al. Genetic variation of Omi/ HtrA2 and Parkinson's disease. Parkinsonism Relat Disord. 2008; 14(7): 539-543, doi: 10.1016/j.parkreldis.2008.08.003, indexed in Pubmed: 18790661.

29. Siuda J, Jasinska-Myga B, Boczarska-Jedynak M, et al. Early-onset Parkinson's disease due to PINK1 p.Q456X mutation-clinical and functional study. Parkinsonism Relat Disord. 2014; 20(11): 12741278, doi: 10.1016/j.parkreldis.2014.08.019, indexed in Pubmed: 25226871.

30. Vilariño-Güell C, Wider C, Ross OA, et al. VPS35 mutations in Parkinson disease. Am J Hum Genet. 2011; 89(1): 162-167, doi: 10.1016/j. ajhg.2011.06.001, indexed in Pubmed: 21763482.

31. Potulska-Chromik A, Hoffman-Zacharska D, Łukawska M, et al. Dopa-responsive dystonia or early-onset Parkinson disease - Genotype-phenotype correlation. Neurol Neurochir Pol. 2017; 51(1): 1-6, doi: 10.1016/j.pjnns.2016.07.013, indexed in Pubmed: 27667361.

32. Schrag A, Schott JM. Epidemiological, clinical, and genetic characteristics of early-onset parkinsonism. Lancet Neurol. 2006; 5(4): 355363, doi: 10.1016/S1474-4422(06)70411-2, indexed in Pubmed: 16545752. 
33. Kitada T, Asakawa S, Hattori N, et al. Mutations in the parkin gene cause autosomal recessive juvenile parkinsonism. Nature. 1998; 392(6676): 605-608, doi: 10.1038/33416, indexed in Pubmed: 9560156.

34. Kasten M, Hartmann C, Hampf J, et al. Genotype-Phenotype Relations for the Parkinson's Disease Genes Parkin, PINK1, DJ1: MDSGene Systematic Review. Mov Disord. 2018; 33(5): 730-741, doi: 10.1002/ mds.27352, indexed in Pubmed: 29644727.

35. Valente EM, Abou-Sleiman PM, Caputo V, et al. Hereditary early-onset Parkinson's disease caused by mutations in PINK1. Science. 2004; 304(5674): 1158-1160, doi: 10.1126/science.1096284, indexed in Pubmed: 15087508.

36. Watzlawik JO, Hou Xu, Fricova D, et al. Sensitive ELISA-based detection method for the mitophagy marker p-S65-Ub in human cells, autopsy brain, and blood samples. Autophagy. 2020 [Epub ahead of print]: 1-16, doi: 10.1080/15548627.2020.1834712, indexed in Pubmed: 33112198.

37. Bonifati V, Rizzu P, Squitieri F, et al. Mutations in the DJ-1 gene associated with autosomal recessive early-onset parkinsonism. Science. 2003; 299(5604): 256-259, doi: 10.1126/science.1077209, indexed in Pubmed: 12446870.

38. Moore DJ, Zhang Li, Dawson TM, et al. A missense mutation (L166P) in DJ-1, linked to familial Parkinson's disease, confers reduced protein stability and impairs homo-oligomerization. J Neurochem. 2003; 87(6): 1558-1567, doi: 10.1111/j.1471-4159.2003.02265.x, indexed in Pubmed: 14713311.

39. Funayama M, Hasegawa K, Ohta $E$, et al. An LRRK2 mutation as a cause for the parkinsonism in the original PARK8 family. Ann Neurol. 2005; 57(6): 918-921, doi: 10.1002/ana.20484, indexed in Pubmed: 15880653.

40. Zimprich A, Biskup S, Leitner P, et al. Mutations in LRRK2 cause autosomal-dominant parkinsonism with pleomorphic pathology. Neuron. 2004; 44(4): 601-607, doi: 10.1016/j.neuron.2004.11.005, indexed in Pubmed: 15541309.

41. Lesage S, Dürr A, Tazir M, et al. French Parkinson's Disease Genetics Study Group. LRRK2 G2019S as a cause of Parkinson's disease in North African Arabs. N Engl J Med. 2006; 354(4): 422-423, doi: 10.1056/NEJMc055540, indexed in Pubmed: 16436781.

42. Ozelius L, Senthil G, Saunders-Pullman R, et al. LRRK2 G2019S as a cause of Parkinson's disease in Ashkenazi Jews. N Engl J Med. 2006; 354(4): 424-425, doi: 10.1056/NEJMc055509, indexed in Pubmed: 16436782.

43. Lesage S, Leutenegger AL, Ibanez P, et al. French Parkinson's Disease Genetics Study Group. LRRK2 haplotype analyses in European and North African families with Parkinson disease: a common founder for the G2019S mutation dating from the 13th century. Am J Hum Genet. 2005; 77(2): 330-332, doi: 10.1086/432422, indexed in Pubmed: 16145815.

44. Zimprich A, Benet-Pagès A, Struhal W, et al. A mutation in VPS35, encoding a subunit of the retromer complex, causes late-onset Parkinson disease. Am J Hum Genet. 2011; 89(1): 168-175, doi: 10.1016/j. ajhg.2011.06.008, indexed in Pubmed: 21763483.

45. Shannon B, Soto-Ortolaza A, Rayaprolu S, et al. Genetic variation of the retromer subunits VPS26A/B-VPS29 in Parkinson's disease. Neurobiol Aging. 2014; 35(8): 1958.e1-1958.e2, doi: 10.1016/j.neurobiolaging.2014.03.004, indexed in Pubmed: 24684791.

46. Polymeropoulos MH, Lavedan C, Leroy E, et al. Mutation in the alpha-synuclein gene identified in families with Parkinson's disease.
Science. 1997; 276(5321): 2045-2047, doi: 10.1126/science.276.5321.2045, indexed in Pubmed: 9197268.

47. Muenter MD, Forno LS, Hornykiewicz 0 , et al. Hereditary form of parkinsonism--dementia. Ann Neurol. 1998; 43(6): 768-781, doi: 10.1002/ana.410430612, indexed in Pubmed: 9629847.

48. Book A, Guella I, Candido T, et al. SNCA Multiplication Investigators of the GEoPD Consortium. A Meta-Analysis of $\alpha$-Synuclein Multiplication in Familial Parkinsonism. Front Neurol. 2018; 9: 1021, doi: 10.3389/ fneur.2018.01021, indexed in Pubmed: 30619023.

49. Ibáñez P, Lesage S, Janin S, et al. French Parkinson's Disease Genetics Study Group. Alpha-synuclein gene rearrangements in dominantly inherited parkinsonism: frequency, phenotype, and mechanisms. Arch Neurol. 2009; 66(1): 102-108, doi: 10.1001/archneurol.2008.555, indexed in Pubmed: 19139307.

50. Fan TS, Lin HI, Lin CH, et al. Lack of CHCHD2 mutations in Parkinson's disease in a Taiwanese population. Neurobiol Aging. 2016; 38: 218. e1-218.e2, doi: 10.1016/j.neurobiolaging.2015.11.020, indexed in Pubmed: 26725463.

51. Vilariño-Güell C, Rajput A, Milnerwood AJ, et al. DNAJC13 mutations in Parkinson disease. Hum Mol Genet. 2014; 23(7): 1794-1801, doi: 10.1093/hmg/ddt570, indexed in Pubmed: 24218364.

52. Huttenlocher J, Krüger R, Capetian P, et al. EIF4G1is neither a strong nor a common risk factor for Parkinson's disease: evidence from large European cohorts: Table1. Journal of Medical Genetics. 2014; 52(1): 37-41, doi: 10.1136/jmedgenet-2014-102570.

53. Strauss KM, Martins LM, Plun-Favreau $\mathrm{H}$, et al. Loss of function mutations in the gene encoding Omi/HtrA2 in Parkinson's disease. Hum Mol Genet. 2005; 14(15): 2099-2111, doi: 10.1093/hmg/ddi215, indexed in Pubmed: 15961413.

54. Soto-Ortolaza Al, Ross OA. Genetic susceptibility variants in parkinsonism. Parkinsonism Relat Disord. 2016; 22 Suppl 1: S7-11, doi: 10.1016/j.parkreldis.2015.09.011, indexed in Pubmed: 26414118.

55. Kim MS, Patel KP, Teng AK, et al. Genetic disease risks can be misestimated across global populations. Genome Biol. 2018; 19(1): 179, doi: 10.1186/s13059-018-1561-7, indexed in Pubmed: 30424772.

56. Zhao F, Bi L, Wang W, et al. Mutations of glucocerebrosidase gene and susceptibility to Parkinson's disease: An updated meta-analysis in a European population. Neuroscience. 2016; 320: 239-246, doi: 10.1016/j.neuroscience.2016.02.007, indexed in Pubmed: 26868973.

57. Jamrozik Z, Lugowska A, Kosiorowski D. Beta-Glucocerebrosidase Gene Mutations P.Asn409Ser and P.Leu483Pro in Polish Patients with Parkinson's Disease. Journal of Neurology and Neuroscience. 2015; 06(04), doi: 10.21767/2171-6625.100054.

58. Malec-Litwinowicz M, Plewka A, Plewka D, et al. The relation between plasma $\alpha$-synuclein level and clinical symptoms or signs of Parkinson's disease. Neurol Neurochir Pol. 2018; 52(2): 243-251, doi: 10.1016/j.pjnns.2017.11.009, indexed in Pubmed: 29342421.

59. Iwaki H, Blauwendraat C, Leonard HL, et al. International Parkinson's Disease Genomics Consortium. Genomewide association study of Parkinson's disease clinical biomarkers in 12 longitudinal patients' cohorts. Mov Disord. 2019; 34(12): 1839-1850, doi: 10.1002/ mds.27845, indexed in Pubmed: 31505070.

60. Pierzchlińska A, Białecka M, Kurzawski M, et al. The impact of Apolipoprotein E alleles on cognitive performance in patients with Parkinson's disease. Neurol Neurochir Pol. 2018; 52(4): 477-482, doi: 10.1016/j. pjnns.2018.04.003, indexed in Pubmed: 29776682. 
61. Białecka M, Droździk M, Honczarenko K, et al. Catechol-0-methyltransferase and monoamine oxidase $B$ genes and susceptibility to sporadic Parkinson's disease in a Polish population. Eur Neurol. 2005; 53(2): 68-73, doi: 10.1159/000084302, indexed in Pubmed: 15753616.

62. Białecka M, Droździk M, Kłodowska-Duda $G$, et al. The effect of monoamine oxidase $B(\mathrm{MAOB})$ and catechol-0-methyltransferase (COMT) polymorphisms on levodopa therapy in patients with sporadic Parkinson's disease. Acta Neurol Scand. 2004; 110(4): 260-266, doi: 10.1111/j.1600-0404.2004.00315.x, indexed in Pubmed: 15355491.

63. Bialecka M, Klodowska-Duda G, Kurzawski M, et al. Interleukin-10 gene polymorphism in Parkinson's disease patients. Arch Med Res. 2007; 38(8): 858-863, doi: 10.1016/j.arcmed.2007.06.006, indexed in Pubmed: 17923267.

64. Bialecka M, Kurzawski M, Klodowska-Duda G, et al. Polymorphism in semaphorin $5 \mathrm{~A}$ (Sema5A) gene is not a marker of Parkinson's disease risk. Neurosci Lett. 2006; 399(1-2): 121-123, doi: 10.1016/j.neulet.2006.01.038, indexed in Pubmed: 16481103.

65. Białecka M, Kurzawski M, Vlaykova T, et al. Effects of common functional MMP12 gene polymorphisms on PD in a Polish population. Neurol Neurochir Pol. 2017; 51(5): 347-353, doi: 10.1016/j. pjnns.2017.06.001, indexed in Pubmed: 28655442.

66. Dachsel JC, Wider C, Vilariño-Güell C, et al. Death-associated protein kinase 1 variation and Parkinson's disease. Eur J Neurol. 2011; 18(8): 1090-1093, doi: 10.1111/j.1468-1331.2010.03255.x, indexed in Pubmed: 21749573.

67. Gaweda-Walerych K, Safranow K, Maruszak A, et al. Mitochondrial transcription factor $A$ variants and the risk of Parkinson's disease. Neurosci Lett. 2010; 469(1): 24-29, doi: 10.1016/j.neulet.2009.11.037, indexed in Pubmed: 19925850.

68. Jasinska-Myga B, Wider C, Opala G, et al. GRN 3'UTR+78 C>T is not associated with risk for Parkinson's disease. Eur J Neurol. 2009; 16(8): 909-911, doi: 10.1111/j.1468-1331.2009.02621.x, indexed in Pubmed: 19473366.

69. Labbé C, Ogaki K, Lorenzo-Betancor O, et al. Role for the microtubule-associated protein tau variant p.A152T in risk of $\alpha$-synucleinopathies. Neurology. 2015; 85(19): 1680-1686, doi: 10.1212/WNL. 0000000000001946 , indexed in Pubmed: 26333800.

70. Müller-Nedebock AC, Brennan RR, Venter M, et al. The unresolved role of mitochondrial DNA in Parkinson's disease: An overview of published studies, their limitations, and future prospects. Neurochem Int. 2019; 129: 104495, doi: 10.1016/j.neuint.2019.104495, indexed in Pubmed: 31233840.

71. Peplonska B, Safranow K, Gaweda-Walerych K, et al. TOMM40 and APOE common genetic variants are not Parkinson's disease risk factors. Neurobiol Aging. 2013; 34(8): 2078.e1-2078.e2, doi: 10.1016/j.neurobiolaging.2013.02.018, indexed in Pubmed: 23522842.

72. Pepłońska B, Zekanowski C, Religa D, et al. Strong association between Saitohin gene polymorphism and tau haplotype in the Polish population. Neurosci Lett. 2003; 348(3): 163-166, doi: 10.1016/ s0304-3940(03)00788-2, indexed in Pubmed: 12932819.

73. Puschmann A, Verbeeck C, Heckman MG, et al. Human leukocyte antigen variation and Parkinson's disease. Parkinsonism Relat Disord. 2011; 17(5): 376-378, doi: 10.1016/j.parkreldis.2011.03.008, indexed in Pubmed: 21482477.

74. Rayaprolu S, Mullen B, Baker M, et al. TREM2 in neurodegeneration: evidence for association of the $\mathrm{p} . \mathrm{R} 47 \mathrm{H}$ variant with fronto- temporal dementia and Parkinson's disease. Mol Neurodegener. 2013; 8: 19, doi: 10.1186/1750-1326-8-19, indexed in Pubmed: 23800361.

75. Ross OA, Heckman MG, Soto Al, et al. Dopamine beta-hydroxylase $-1021 C>T$ association and Parkinson's disease. Parkinsonism Relat Disord. 2008; 14(7): 544-547, doi: 10.1016/j.parkreldis.2008.07.002, indexed in Pubmed: 18722802.

76. Soto-Ortolaza Al, Behrouz B, Wider C, et al. Calbindin-1 association and Parkinson's disease. Eur J Neurol. 2010; 17(2): 208-211, doi: 10.1111/j.1468-1331.2009.02769.x, indexed in Pubmed: 19674066.

77. Tan EK, Drozdzik M, Bialecka M, et al. Analysis of MDR1 haplotypes in Parkinson's disease in a white population. Neurosci Lett. 2004; 372(3): 240-244, doi: 10.1016/j.neulet.2004.09.046, indexed in Pubmed: 15542248.

78. von Otter M, Landgren S, Nilsson S, et al. Association of Nrf2-encoding NFE2L2 haplotypes with Parkinson's disease. BMC Med Genet. 2010; 11: 36, doi: 10.1186/1471-2350-11-36, indexed in Pubmed: 20196834.

79. Truban D, Hou Xu, Caulfield TR, et al. PINK1, Parkin, and Mitochondrial Quality Control: What can we Learn about Parkinson's Disease Pathobiology? J Parkinsons Dis. 2017; 7(1): 13-29, doi: 10.3233/ JPD-160989, indexed in Pubmed: 27911343.

80. Noack H, Bednarek T, Heidler J, et al. TFAM-dependent and independent dynamics of mtDNA levels in $\mathrm{C} 2 \mathrm{C} 12$ myoblasts caused by redox stress. Biochim Biophys Acta. 2006; 1760(2): 141150, doi: 10.1016/j.bbagen.2005.12.007, indexed in Pubmed: 16439064.

81. Gaweda-Walerych K, Maruszak A, Safranow K, et al. Mitochondrial DNA haplogroups and subhaplogroups are associated with Parkinson's disease risk in a Polish PD cohort. J Neural Transm (Vienna). 2008; 115(11): 1521-1526, doi: 10.1007/s00702-008-0121-9, indexed in Pubmed: 18810306.

82. Liu Y, Zhang M, Hao W, et al. Matrix metalloproteinase-12 contributes to neuroinflammation in the aged brain. Neurobiol Aging. 2013; 34(4): 1231-1239, doi: 10.1016/j.neurobiolaging.2012.10.015, indexed in Pubmed: 23159549.

83. Michałowska M, Chalimoniuk M, Jówko E, et al. Gene polymorphisms and motor levodopa-induced complications in Parkinson's disease. Brain Behav. 2020; 10(3): e01537, doi: 10.1002/brb3.1537, indexed in Pubmed: 32022467.

84. Labbé C, Ogaki K, Lorenzo-Betancor O, et al. Exonic Re-Sequencing of the Chromosome 2q24.3 Parkinson's Disease Locus. PLoS One. 2015; 10(6): e0128586, doi: 10.1371/journal.pone.0128586, indexed in Pubmed: 26090850.

85. Mizuta I, Tsunoda T, Satake W, et al. Calbindin 1, fibroblast growth factor 20, and alpha-synuclein in sporadic Parkinson's disease. Hum Genet. 2008; 124(1): 89-94, doi: 10.1007/s00439-008-0525-5, indexed in Pubmed: 18568448.

86. Krygowska-Wajs A, Kachergus JM, Hulihan MM, et al. Clinical and genetic evaluation of 8 Polish families with levodopa-responsive parkinsonism. J Neural Transm (Vienna). 2005; 112(11): 1487-1502, doi: 10.1007/ s00702-005-0290-8, indexed in Pubmed: 15785861.

87. Krygowska-Wajs A, Hussey JM, Hulihan M, et al. Two large Polish kindreds with levodopa-responsive Parkinsonism not linked to known Parkinsonian genes and loci. Parkinsonism Relat Disord. 2003; 9(4): 193-200, doi: 10.1016/s1353-8020(02)00036-6, indexed in Pubmed: 12618053. 
88. Figura M, Friedman A. In search of Parkinson's disease biomarkers - is the answer in our mouths? A systematic review of the literature on salivary biomarkers of Parkinson's disease. Neurol Neurochir Pol. 2020; 54(1): 14-20, doi: 10.5603/PJNNS.a2020.0011, indexed in Pubmed: 32003440.

89. Schneider SA, Alcalay RN. Precision medicine in Parkinson's disease: emerging treatments for genetic Parkinson's disease. J Neurol. 2020; 267(3): 860-869, doi: 10.1007/s00415-020-09705-7, indexed in Pubmed: 31974807.
90. Fiandaca MS, Lonser RR, Elder JB, et al. Advancing gene therapies, methods, and technologies for Parkinson's Disease and other neurological disorders. Neurol Neurochir Pol. 2020; 54(3): 220-231, doi: 10.5603/PJNNS.a2020.0046, indexed in Pubmed: 32557526.

91. Padmanabhan S, Polinski NK, Menalled LB, et al. The Michael J. Fox Foundation for Parkinson's Research Strategy to Advance Therapeutic Development of PINK1 and Parkin. Biomolecules. 2019; 9(8), doi: 10.3390/biom9080296, indexed in Pubmed: 31344817. 